\title{
El silencio. Su sentido potenciador y su sentido depotenciador de la vida ${ }^{1}$
}

\author{
Dra. Sara Leticia Molina²
}

Recibido: 24 de noviembre de 2018 - Aprobado: 26 de enero de 2019

\begin{abstract}
Resumen
El escrito aborda el problema del silencio en un doble sentido. Por un lado, como depotenciador y destructor de la vida humana; por otro lado, se reflexiona sobre su incidencia en el crecimiento del poder de la vida. Se apela a los escritos testimoniales de Primo Levi sobre su encierro en los campos de concentración nazi, pues constituyen un soporte útil para pensar el problema que convoca este trabajo. Hay expresiones del silencio involuntarias, inconscientes, propias de la actividad que, si bien acaece en el cuerpo de cada quien, sin embargo, resulta extraña a la conciencia y decisión del afectado. La tópica establecida por Lacan, especialmente el registro de lo Real, guía el abordaje de este punto. La valoración del silencio como potenciador de la vida es tratada a partir de la obra de Nietzsche, en los textos que tocan el problema de la soledad.
\end{abstract}

Palabras clave: silencio - Nietzsche - crecimiento y depotenciación de la vida - Real lacaniano - Primo Levi

\section{Silence. Its enhancing sense and its diminishing sense for life}

\begin{abstract}
This article addresses the problem of silence from a double meaning. On the one hand, as a diminishing and destructive force for human life; and on the other, its role in the enhancement of the power of life. The testimonial writings of Primo Levi on his enclosure in Nazi concentration camps are taken as a useful support when addressing the problem presented by this
\end{abstract}

1 Este artículo es un recorte del trabajo en desarrollo Memoria y olvido. Sentidos del silencio, que forma parte del Proyecto de investigación: Comunidades políticas: trayectorias categoriales, experiencias socio-educativas y prácticas jurídicas. Perspectivas desde América Latina; Convocatoria PICTO- Universidad Nacional de Cuyo 2016.

2 Licenciada y Doctora en Filosofía por la Facultad de Filosofía y Letras, Universidad Nacional de Cuyo, Mendoza, República Argentina. Investigadora en la Facultad de Filosofía y Letras, Universidad Nacional de Cuyo, Mendoza. Contacto: saraleticiam@ yahoo.com.ar

ORCID: https://orcid.org/0000-0002-3176-6418 
article. There are expressions of involuntary, unconscious silence inherent to an activity that, while falling upon the body of each person, is foreign to the consciousness and decision of the affected party. The topic established by Lacan, particularly the Real, helps guide the treatment of this point. The valuation of silence in its enhancement of life is addressed based on Nietzsche and his texts on the problem of solitude.

Key words: silence - Nietzsche - growth and diminishment of life Lacanian real - Primo Levi

\title{
0 silêncio. Seu sentido potenciador e seu sentido depotenciador da vida
}

\begin{abstract}
Resumo
O escrito aborda o problema do silêncio em um duplo sentido: por uma parte, quanto depotenciador e destruidor da vida humana; por outra, reflete-se sobre sua incidência no crescimento do poder da vida. Apela-se aos escritos testemunhais de Primo Levi sobre seu confinamento nos campos de concentração nazistas, pois constituem um suporte útil para pensar o problema que convoca este trabalho. Há expressões do silêncio involuntárias, inconscientes, próprias da atividade que, ainda que tenha lugar no corpo de cada um, é estranha à consciência e decisão do afetado. A tópica estabelecida por Lacan, especialmente no registro do Real, orienta a abordagem deste ponto. A valoração do silêncio como potenciador da vida é tratada a partir da obra de Nietzsche, nos textos que tocam o problema da solidão.

Palavras-chave: silêncio - Nietzsche - crescimento e depotenciação da vida - Real lacaniano - Primo Levi
\end{abstract}

\section{Introducción}

El propósito de este artículo es indagar acerca del alcance del silencio y el significado que esta dimensión, en constante presencia actuante, imprime en la vida humana. Guiados por la filosofía de Nietzsche, uno de cuyos pilares es el fluir de los sentidos, abordamos el problema del silencio en un doble significado. Por un lado, el que actúa en detrimento de la vida; por otro, la expresión del mutismo que opera a favor del crecimiento del poder ${ }^{3}$ de la misma.

3 Es preciso aclarar que Nietzsche establece la categoría de poder en tanto fuerza 
Desde la perspectiva nietzscheana, entendemos que el problema de la vida no es asimilable a la idea del "impulso o instinto de conservación", aunque lo incluye. Aquí no se trata de la lucha por mantenerla a cualquier precio; el concepto, cercano a Spinoza, en tanto confiere relevancia especial a los impulsos, sin embargo, se distancia en el alcance de los mismos cuando postula que el impulso procura la preservación en el propio ser. Acrecentar el poder de la vida es mucho más que tratar de conservarla, pues ella puede conservarse en un debilitamiento progresivo aun en condiciones degradantes de humillación, esclavización, denigración, sometimiento, negación de la dignidad, etc.

En la misma línea, entendemos la categoría de "vida" en una extensión y en una profundidad que abarca desde las manifestaciones más simples y básicas de la naturaleza hasta las expresiones más sublimes de lo humano. En ese sentido, concebimos los procesos de pensamiento filosófico en un indisociable entrelazamiento con los fenómenos corporales; y entendemos que los fenómenos de la vida sensible no verbalizados ocupan un lugar de suma relevancia, tanto en el pensamiento como en las prácticas. El que no nos percatemos de ello no invalida la tesis.

El valor positivo, la relevancia espiritual y/o social, asignados al silencio, así como su desplazamiento o menoscabo, difieren profundamente en contextos culturales disímiles. Presentamos una serie de experiencias propias de sociedades o contextos socioculturales distantes, divergentes, o con escasos rasgos en común, a modo de acercamiento al problema. Lo que sigue es apenas un escueto muestrario delator del papel fundamental que el silencio juega en la vida humana.

de crecimiento de la vida, distinguiéndolo del poder económico, político, religioso, militar, que somete usurpando la fuerza de otros. Tanto en uno como en otro caso, se trata del cruce de fuerzas espaciotemporales en constante e indetenible movimiento controversial. Tratamos el tema in extenso en Molina, S. Leticia. El cuerpo y el devenir de las fuerzas en Nietzsche. Buenos Aires: Biblos, 2017. 
George Steiner (2003) afirma que la especialización científica desplazó el lenguaje verbal a un segundo plano, reemplazándolo por fórmulas matemáticas y algoritmos diversos. Otras expresiones culturales ajenas a la tradición griega y judeo-cristiana confieren el señorío a la actividad silenciosa. El escritor menciona el taoísmo y el budismo en tanto prácticas religiosas, para las cuales alcanzar el estado de la pura contemplación solitaria y silente es el grado más alto al que puede aspirar un ser humano. El misticismo, el encierro monástico practicado en algunas creencias se acerca de alguna manera a la modalidad oriental. Sin embargo, tal como afirma Steiner, desde una visión religiosa, mientras para un budista la comunión con el infinito es motivo de máxima plenitud y felicidad, Pascal, cercano a la sensibilidad occidental, "dice que el silencio del espacio cósmico le aterra" (31).

Una valoración muy alejada de lo anterior, pero de importancia vital se constata en las prácticas prelógicas carentes del lenguaje verbal que Bourdieu (Molina 2017 237) descubre en la comunidad argelina, en la que gestos y movimientos corporales transmitidos por la costumbre a través de la historia conservan casi inalterada la estructura social de relaciones de dominio. Solo el intento de modificar en algo la praxis da lugar a la palabra que delibera y sanciona.

El principio organizador de la prelógica se establece en una serie de oposiciones que se localizan en todos los órdenes de la vida: familiar, sexual, laboral, económico, cultural; determinando las prácticas y asignándoles sentido: arriba/ abajo, abierto/cerrado, oscuro/lleno de luz... El hilado de la trama ofrece una coherencia valorativa, descifrable en la observación de la acción, de los movimientos corporales, de los gestos (Id. 238).

Desde una perspectiva muy diferente, Felix Schwartzmann dirige la mirada sobre el hombre de campo sudamericano, sosteniendo que los vínculos humanos forjados por la vida cotidiana se cruzan y son favorecidos por el nexo más directo y vivencial que la vida íntima mantiene con la naturaleza y el cosmos. La relación primordial con la naturaleza, parcialmente virgen en tierras americanas, trasciende a la historia y determina un rasgo original, ausente en Europa, cuya 
intervención técnica de control y sometimiento lo impide. El vínculo con el otro se halla condicionado por aquella conexión intuitiva, libre de palabras (Schwartzmann 1992).

Sin entrar en detalle, es fácil comprobar la eficacia de la imitación exenta de explicaciones en los aprendizajes de habilidades que protagonizan los pueblos originarios nuestroamericanos, incorporados a través de actividades familiares, prácticas estas muy diferentes a la educación verborrágica predominante de las escuelas modernas. Muchos pueblos originarios fueron educados en el silencio y en la escucha silenciosa.

Existen pactos de silencio que encubren hechos históricos deleznables, acaecidos en el campo político, eclesiástico y en otras instituciones. En la actualidad se combinan con otra modalidad del mutismo. Se trata de fenómenos que no requieren justificación elaborada a base de falacias o argumentos ambiguos; simplemente se los niega, se ocultan, no se exhiben por las pantallas, y el montaje de la comunicación se realiza en gran medida sobre un acuerdo tácito: el acontecimiento que no se muestra, no existe.

No es nuestro propósito detenernos en cada una de las circunstancias históricas, culturales y políticas presentadas sintéticamente, pues su tratamiento excede ampliamente las posibilidades de este escrito. Fueron escogidas porque exhiben un denominador común: en todas ellas el silencio juega un rol determinante y podrían ser recorridas desde una pregunta axial que guía nuestra reflexión: ¿se trata de experiencias que acrecientan el poder de la vida o, por el contrario, lo debilitan?

La eficacia y la operatividad del silencio tienen su motor principal en la subjetividad de los seres humanos que, en su singularidad, lo promueven, lo interrumpen, lo mantienen, lo alimentan o lo violan -para bien o para mal- bajo el condicionamiento decisivo de la tecnología comunicacional, cuyo poder crece día a día en el sistema capitalista. De ahí que nuestro interés se centre en un segundo interrogante: ¿qué papel juega la subjetividad en la operatividad del silencio orientado a la potenciación de la vida o, en el extremo opuesto, dirigido a su agotamiento y aniquilación? 
Steiner (2003) asevera:

Lo visto puede ponerse en palabras; lo sentido puede presentarse a algún nivel anterior o exterior al lenguaje. La sintaxis tradicional organiza nuestra percepción en esquemas lineales y monistas. Estos esquemas deforman o sofocan el juego de las energías inconscientes, la multitudinaria vida interior, como revelaron... Dostoievski, Nietzsche y Freud (39-44).

En consonancia con estas palabras de Steiner, aseveramos que el silencio, en tanto personaje invisible e intangible, talla en la intimidad personal desde la dimensión inconsciente, formando parte irrecusable en la constitución de la subjetividad, incidiendo y condicionando los procesos sociales, políticos y económicos, y, nos atrevemos a aseverar, con frecuencia resulta determinante en las transformaciones culturales.

Sin embargo, no es nuestra intención tratar el tema del silencio como límite o imposibilidad del lenguaje, de aquello que no cabe en una proposición o de lo que no puede ser conceptualmente expresado, según el enfoque de Wittgenstein. Aunque, según asevera Steiner, para el filósofo vienés:

El lenguaje solo puede ocuparse significativamente de un segmento particular y restringido de la realidad. El resto $-\mathrm{y}$, presumiblemente, la mayor parte- es silencio (...). El silencio, que en cada momento rodea la desnudez del discurso, parece, en virtud de la perspicacia de Wittgenstein, no tanto un muro como una ventana (Steiner 2003 38).

Desde la metáfora de la ventana aludida por el filósofo, dejamos de lado lo que atañe a la impotencia de la palabra, para ahora reflexionar sobre el silencio, considerado aquí como una de las experiencias que confieren vigor a la fuerza vital de los seres humanos o lo menguan. En el primer caso, la fuerza prospera gracias a la potencia creadora y constructiva de la vida misma; en el segundo, se trata del sentido antagónico, esto es, de la experiencia depotenciadora y destructora con la que se enfrenta, a veces librando terribles batallas en el intento de lograr la hegemonía. 
En la puja tensional, vida y muerte se alternan en el comando de los sujetos y uno de los polos puede resultar definitivamente victorioso.

Las reflexiones que presentamos a continuación procuran aproximar una respuesta tentativa a esta pregunta. Al marco nietzscheano mencionado arriba como apoyo fundamental, agregamos la importante guía que nos ofrece el psicoanálisis, en algunos aspectos específicos, y el aporte testimonial de Primo Levi, valiosísimo material que permite hilar fino en este problema de difícil acceso.

\section{El silencio del terror en la violencia del poder que somete 0 aniquila}

Nos referimos en este punto al papel que juega el silencio en la acción devastadora del terrorismo de Estado. Los efectos de la violencia ejercida desde las sombras, en recintos mudos, son intangibles en su terrible magnitud, dado que las marcas más profundas son inconscientes, y porque son inconscientes perduran indefinidamente en el tiempo. La dictadura militar argentina apeló a ese tipo de mecanismos con la complicidad de sectores civiles y de la iglesia. En ese sentido, Alejandro Kaufman (2013) analiza la conexión de esta última con el estado terrorista. La "institución teológico-política", dice Kaufman, se erige en "maquinaria de producción multitudinaria de subjetividad" (Ibíd.).

El investigador argentino afirma que el exterminio durante la dictadura, como en el régimen nazi, fue posible porque la subjetividad fue administrada con eficacia. Uno de los recursos empleados fue el silencio, que la iglesia mantuvo en complicidad cuando concedió el espacio de confesión y eucaristía a los perpetradores del exterminio. También lo hizo respecto de la criminalidad mayor, como fue la desaparición de los cuerpos y la usurpación de los bebés.

Ponderando situaciones semejantes, Primo Levi (1989) afirma:

Me he limitado casi con exclusividad a los Lager nacionalsocialistas, porque son solo éstos los que he conocido por experiencia propia. También he tenido sobre ellos una 
copiosa experiencia indirecta, a través de los libros leídos, relatos escuchados y encuentros con lectores de mis dos primeros libros. Además, hasta el momento en que escribo y, no obstante el horror de Hiroshima y Nagasaki, la vergüenza de los Gulag, la inútil y sangrienta campaña de Vietnam, el autogenocidio de Camboya, los desparecidos en la Argentina, y las muchas guerras atroces y estúpidas a que hemos venido asistiendo, el sistema de campos de concentración nazi continúa siendo un unicum, en cuanto a magnitud y calidad (9).

La cita es extraída de sus escritos testimoniales sobre el atroz encierro en los Lager de la Alemania nazi y que fueron vertidos en su Trilogía. Esta obra constituye el soporte fenomenológico desde el cual buscaremos acercarnos a la fibra íntima de la subjetividad en los dos carriles del silencio que se disputan el predominio. La elegimos porque, por un lado, se trata de relatos que brotan de la misma experiencia vivencial de Levi, cuyo fin no fue hacer ciencia histórica sino contar lo vivido para que la humanidad no lo olvide. Por otro lado, nos colocamos frente a situaciones extremas, en las que vida y muerte se conjugaron y convivieron durante mucho tiempo en la forma humana y en la forma bestial o monstruosa. Estas condiciones hacen de la narración de Levi el material idóneo para pensar sobre el tema de este trabajo.

En relación a la cita de Levi, nos preguntamos si habrá una expresión de silencio más atroz que el que habitó los cuerpos exangües de los judíos víctimas del régimen nazi, sometidos a las más terribles formas de maltrato, con el fin de ser eliminado todo vestigio de humanidad antes de ser conducidos a la muerte.

El testimonio de Primo Levy es revisado detalladamente por Joan B. Llinares (2016), quien recorre las páginas de la Trilogía y establece una tipología del silencio provocado por el terror. En relación con el tema que nos ocupa y trayendo aquí la dimensión sintiente del pensar, lo primero que nos impacta en el escrito es la advertencia que Llinares hace a sí mismo al emprender la lectura. Frente al testimonio de las más crueles manifestaciones de la maldad, asegura que la "medita- 
ción" y "la lectura serena" son imperativos que evitan "los hechizos del morbo y la venganza" (2).

Son varios los tipos de silencio en los que el filósofo agrupa algunos de los aspectos más siniestros de los padecimientos vividos por los prisioneros en los Lager; pero nos interesa describir la situación límite, en la que se conjugan los diferentes tipos: el del silencio de la deshumanización como antesala de la muerte. Es el de los prisioneros que se vieron privados de la mínima comunicación, que no tuvieron contacto humano alguno durante la estadía en los campos de exterminio, ni siquiera con los guardias, pues estos proferían gritos y alaridos mezclados con golpes, para dictar órdenes incomprensibles. Aquellos, invadidos por el terror, enmudecieron ante la ausencia absoluta de canales de comunicación, y sus vidas se extinguieron en poco tiempo. Otros no solo sellaron su boca sino también su mente y se convirtieron en autómatas, eran "los hundidos", llamados "musulmanes" (1987). Primo Levi los describe con el ánimo de proporcionar documentación que facilite un estudio sereno de ciertos rasgos del alma humana.

Su vida es breve pero su número es desmesurado; son ellos, los Muselmänner, los hundidos, los cimientos del campo, ellos, la masa anónima, continuamente renovada y siempre idéntica, de no hombres que marchan y trabajan en silencio, apagada en ellos la llama divina, demasiados vacíos ya para sufrir verdaderamente. Se duda en llamarlos vivos: se duda en llamar muerte a su muerte, ante la que no temen porque están demasiado cansados para comprenderla.

Son los que pueblan mi memoria con su presencia sin rostro, y si pudiese encerrar todo el mal de nuestro tiempo en una imagen, escogería esta imagen, que me resulta familiar: un hombre demacrado, con la cabeza inclinada y las espaldas encorvadas, en cuya cara y en cuyos ojos no se puede leer ni una huella de pensamiento (1987 53-54).

El silencio de los grandes acontecimientos sin nombrar, desplazados de la mirada social o sepultados en la sombra de la historia, priva a los seres humanos del legítimo protagonismo histórico. El silencio de 
las víctimas del terror, del aislamiento forzado, socava la subjetividad o la arrasa directamente. Estos fenómenos dan cuenta de un sentido del silencio depotenciador o debilitador de la vida.

En su libro Los Hundidos y los Salvados (1989), Primo Levi habla de la "violencia inútil" (45), y lo hace a sabiendas de la inutilidad de cualquier tipo de violencia. Sin embargo, justifica los términos explicando que lo destacable es la pregunta acerca del sentido que tenía producir el mayor sufrimiento, más allá del cumplimiento del objetivo buscado. Muchos prisioneros se sintieron avergonzados al constatar "el goce en el mal del prójimo" (Ibíd.), al corroborar el nivel de monstruosidad que puede alcanzar un ser perteneciente a la misma especie homo. Esa vergüenza contribuyó también a socavar las pocas reservas de energía vital que les quedaba.

"La aversión contra los judíos, impropiamente llamada antisemitismo, es un caso particular de un fenómeno más vasto: la aversión contra quien es diferente a uno", afirma Levi (1987 115). Es la expresión mayúscula del odio y el desprecio, pues las acciones seguidas hasta llegar al exterminio eran "ostensiblemente simbólicas" (Id. 117). Levi invoca el recuerdo de los vagones destinados al traslado de ganado, donde amontonaban a judíos, gitanos, eslavos, todos tatuados como los bovinos. Los vagones permanecían cerrados durante todo el viaje, lo que obligaba a esos hombres, mujeres y niños "a yacer días y días en su propia suciedad" (Ibíd.). Para exterminarlos "se usaba el mismo gas venenoso que se usaba para desinfectar [...] los locales infestados de chinches y piojos" (Id. 118). Para Levi, caracterizar el antisemitismo como un fenómeno de intolerancia minimiza los hechos. Ese tipo de explicación le resta magnitud; $y$ "si comprender es imposible, conocer es necesario, porque lo sucedido puede volver a suceder, las conciencias pueden ser seducidas y obnubiladas de nuevo, las nuestras también" (Id. 119).

Estas últimas palabras resultan claves en el contexto de esta exposición. Después de un tiempo de encierro en las condiciones compartidas por todos los prisioneros, el químico italiano fue seleccionado para trabajar en el laboratorio. La actividad se convirtió en una barrera defensiva respecto del trato más brutal; y eso le permitió pensar y guardar en la memoria lo que vio y lo que vivió. Con la derrota del nazismo y la recuperación de 
la libertad, su proyecto fundamental fue registrar todo lo vivido en los escritos cuya edición en principio fue rechazada. Sin embargo, tiempo después, la obra fue publicada y traducida a varios idiomas.

¿Por qué resultan claves aquellas palabras? Evidentemente Levi considera la probabilidad de la repetición del macabro fenómeno. Uno de los factores que gravitan en esa apreciación es la conducta del pueblo alemán.

Es cierto que el terrorismo de Estado es un arma muy fuerte a la que es muy difícil resistir, pero también es cierto que el pueblo alemán, globalmente, ni siquiera intentó resistir. En la Alemania de Hitler se había difundido una singular forma de urbanidad: quien sabía no hablaba, quien no sabía, no preguntaba, quien preguntaba no obtenía respuesta (1987 109).

Muchos alemanes vieron desde afuera la caravana de hombres hundidos, descalzos, caminando rumbo al trabajo esclavo, donde varios caían muertos. Muchos hombres de negocios trabaron relación comercial con la industria producida en los campos de concentración, "eran proveedores de la SS de los Lager [...] solicitaban mano de obra de trabajadores-esclavos [...] Profesores universitarios colaboraban con los centros de investigación médica instituidos por Himmler" (Id. 108).

La situación descripta y silenciada por el pueblo alemán nos conduce a pensar en el acierto de la sospecha de Levi, sintetizada en la singular forma de urbanismo, y dirige nuestra atención hacia los rincones más profundos y oscuros del ser humano, pues las almas no siempre son profundas por la belleza que pueden albergar, también lo son por su contenido execrable. Entre otras razones, por eso tantas cosas se mantienen en secreto.

En ese espacio de horror, habitado "por un rebaño mudo innumerable" (1987 71), donde "cada uno está desesperadamente, ferozmente solo" (Id. 52), y si alguno de los prisioneros encuentra un modo, un arte que le permita evadirse del trabajo más duro, o conseguir "unos gramos más de pan [...] lo mantendrá en secreto (Id. 53). Allí priman 
las miradas hostiles, el mutismo exacerbado, las palabras ambiguas o mentirosas. El instinto social se quiebra.

Sin embargo, en medio de la muchedumbre que cohabita en el encierro y mira con recelo, desconfianza desde una abismal soledad, hostil y ya indiferente frente al dolor y la muerte, Primo Levi (1987) descubre la amistad indestructible de dos o tres "almas bellas", cuya amistad cultiva cotidianamente. "Creo que es a Lorenzo a quien debo el estar hoy vivo; y no tanto por su ayuda material, como por haberme recordado constantemente con su presencia, con su manera tan llana y fácil de ser bueno" (73), que afuera había todavía algo "ajeno al miedo y al odio" (Ibíd.). El otro caso es Alberto, con quien se mantiene unido "por un estrechísimo pacto de alianza, por la que cada bocado 'organizado' es dividido en dos partes rigurosamente iguales" (Id. 83). Alberto se alegra, sin el menor atisbo de envidia, porque Primo ha sido destinado al trabajo en el laboratorio. "La sangre de sus venas es demasiado libre para que mi viejo amigo no domado, piense en arrellanarse en una colocación; su instinto lo conduce a otra parte, hacia otras soluciones, hacia lo imprevisto, lo extemporáneo, lo nuevo" (Ibíd.).

Nos hemos detenido en situaciones extremas; sin embargo, en la interioridad de los seres humanos corrientes conviven estados en los que puede tallar lo mejor y lo peor. Como es sabido, Freud determinó su procedencia en la pulsión de muerte, que, en sus embates, es contrarrestada por Eros. A veces esos estados se superponen, se separan, se solapan, se desplazan o tratan de anularse recíprocamente; pero esto ocurre inconscientemente. Ese movimiento de fuerzas se relaciona con el sentido potenciador o depotenciador de la vida, problema al que nos abocamos en lo que sigue, sin corrernos del hilo conductor seguido hasta aquí, esto es, la vida en su actividad silenciosa.

\section{El límite móvil y difuso que separa el sentido potenciador del sentido depotenciador de la vida}

Hay modos del silencio involuntarios, inconscientes, propios de la actividad que, si bien acaece en el cuerpo de cada quien, sin embargo, 
ella resulta ajena, extraña a la conciencia y decisión del afectado. Así lo revela el psicoanálisis, perspectiva de la que tomaremos una faceta especialmente y a la que nos ceñiremos en el desarrollo de este trabajo. No haremos referencia a casos individuales con afecciones patológicas específicas, pues el tema escapa al propósito de esta exposición, pero vale la pena comentar que, aunque la técnica psicoanalítica emplea la palabra como su principal herramienta de trabajo, sin embargo, los espacios silentes son tan importantes que, aun cuando el analizante permanezca callado durante toda una sesión o en el transcurso de varias sesiones, ello no significa ausencia de actividad psíquica. Tras ese mutismo tal vez se esté librando una dura lucha entre lo reprimido y el intento por encontrar algo que permanece oculto (Lacan 2000). "La impresión del mundo externo en bruto, original, primitiva está fuera del campo que corresponde a una experiencia apreciable" (2000 66); es lo que permanece oculto, pero se inscribe en una estructura significante. Con el paso del tiempo, en los primeros años de vida, "una inscripción más organizada en función de los recuerdos, parecerá constituir más especialmente un inconsciente" (Ibíd.), que se estructura como lenguaje y se rige por el principio de placer.

El cuerpo acusa recibo de esta intensa actividad ${ }^{4}$, pero el circuito que se establece entre la represión primordial y la estructura significante es extraña a la consciencia que, sin embargo, elabora las representaciones en función de aquellas primeras impresiones; de ahí que éstas pueden captarse solo por sus efectos secundarios. De modo que la emisión de

4 En otro sentido, aunque no extraño al psicoanálisis, la filosofía política de Espósito aborda el problema de la relación tensional entre la dimensión subjetiva y la comunidad, y en esa tensión se aprecia la actividad del sujeto, exenta de palabras. Desde una realidad europea actual, Roberto Espósito habla de vacío, fractura, quiebre, fisura, movimiento subjetivo que realiza la vida frente a la amenaza de la muerte. Cuando se nombran estos estados duraderos o instantáneos, sociales o personales, se los interpreta, pero la palabra no es espejo ni efecto inmediato de lo que acaece. El filósofo italiano ve allí el juego entre lo externo y lo interno marcando el vuelco de la subjetividad, que para constituirse como tal requiere de este enlace con lo exterior, pero que, si se exteriorizara o saliera de sí totalmente, desaparecería. Esa instancia, que podríamos llamar metafóricamente como puente tendido entre la interioridad del individuo y la comunidad a la que pertenece, opera calladamente. Cf. Espósito, Roberto. Communitas. Origen y destino de la comunidad. Buenos Aires: Amorrortu, 2003. 
un juicio ajustado al principio de realidad resulta de un acomodamiento en gran medida ficticio, porque se halla ligado a lo reprimido, dirigido por el principio de placer (Freud 1992 253, 254). "Para Lacan, el ser vivo deviene sujeto a través de la captura de la lengua" (Alemán 2016b 64), pero, debido al proceso brevemente descrito, ese "sujeto emerge dividido" (Ibíd.). La escisión es prediscursiva, muda.

Por lo tanto, una parte del sujeto permanece oculto, es incognocible, inescrutable, inaccesible. Se trata de lo Real, dimensión que entrelazada con el orden Imaginario y el Simbólico, configura la estructura de la vida psíquica establecida por Lacan. Estas dos últimas instancias diseñan las imágenes, los gestos miméticos, el discurso socialmente identificatorio. Lo Real no habla.

Pero la teoría lacaniana camina fundamentalmente al compás de las transformaciones culturales de Occidente, de modo que, en el devenir teórico, el lugar determinante que en los años 60 era ocupado por lo Simbólico, a partir de 1970 es reemplazado por lo Real, deseante de placer.

En el marco de este trabajo importa detenernos en ese campo al que Lacan atribuyó relevancia determinante. En él, la pulsión de muerte tiene su reinado, como amenaza latente o en acto. Lo real no es incognocible debido al límite del entendimiento, en el sentido del noumenon kantiano, sino porque esa dimensión de la vida psíquica escapa a las posibilidades de la simbolización. En Kant, aun cuando la cosa en sí resulta incognocible, ella parece cubierta de una aureola de pureza, pues la Razón ilustrada está libre de sospecha: lo que falla es el uso; en cambio para Lacan, en el momento en que la capacidad de simbolizar se anula, lo que sobreviene, o al menos amenaza, es lo peor que la condición humana puede albergar.

Sin embargo, subraya Jorge Alemán (2016 a), en ese mismo escondrijo se erige el lugar de la singularidad de cada quien. En ese terreno fronterizo subraya el protagonismo de lo Real, que distingue de la realidad, siguiendo la definición categorial de Lacan. La realidad se construye en la conjugación de lo Simbólico y lo Imaginario. Lo Real, absolutamente inconsciente, la excede, o, podríamos decir, salta, sortea, el campo de la realidad. Es la dimensión del peligro, pero también el punto o 
el intersticio donde se juega la singularidad insustituible inherente a la humana condición y que permite al ser humano tomar decisiones. Ese espacio íntimo ha sido y es asediado a través de la historia por regímenes políticos distintos -desde hace muchos años ya por el capitalismo neoliberal-, que tratan de usurparlo debilitándolo, llegando a su aniquilación en los totalitarismos.

Dijimos que el sujeto se forja dividido, y la parte tachada es ese Real insondable, constitutivo del sujeto y determinante de la insustituible singularidad de cada ser humano. Según Alemán (2016 b), el error de algunos enfoques filosóficos es confundir la subjetividad con el sujeto. La primera se construye históricamente y en menor o mayor proporción es producida por el poder económico, político, militar, religioso, etc. "Una cosa es la subjetividad construida y producida, y otra cosa es el sujeto, que por definición no puede ser producido. El sujeto es un efecto del lenguaje" (126). Alemán sostiene que la parte tachada del sujeto, la que determina su escisión irrecusable, es inapropiable (2016b 126-127); pues el poder dominador se hace con el orden simbólico y si logra capturar la dimensión insondable de aquel, lo que él denomina "el crimen perfecto" (67) ya habría sucedido; y "la historia sería la historia de los campos de concentración" (131). Si ocurren fenómenos políticos, sociales y culturales, que intentan romper la lógica criminal del capitalismo es gracias a que hay algo estructural en el sujeto que es inapropiable.

La subjetividad se construye en el anudamiento de lo Imaginario, lo Simbólico y lo Real. La realidad en la que el ser humano se halla inmerso depende de la realidad psíquica del sujeto; siempre es fantasmática porque es una construcción del sujeto, es una proyección de eso que el sujeto construye en su mente. Lo imaginario y lo simbólico velan lo Real. Lo Real queda recubierto por esa construcción imaginaria simbólica. Pero el velo que lo recubre no se traduce en clausura, pues su actividad no se detiene, no cesa de incidir en los otros dos campos, de imbricarse con ellos.

Desde la visión psicoanalítica lacaniana, nutrida por los aportes de Jorge Alemán en este caso, "se trata del lugar donde la voz del cuerpo 
se cruza con el significante del sujeto" (2016b 135). El anudamiento de fuerza pulsional y palabra, que Lacan designa con el "neologismo lalengua" (2016a 14), hace posible la diferencia de la singularidad, la cual introduce una cuña en lo igual homogeneizante montado por los poderes dominantes.

La diferencia singularizante sigue el camino que acrecienta el poder de la vida, dirigido por el principio de placer; o, lo contrario, se inclina hacia las formas siniestras de la violencia, con lo monstruoso, lo ominoso, que brotan en el contacto con el otro y es expresión de un plus de goce emergente de la pulsión de muerte. Estas manifestaciones de la vida en el ser humano no estarían demasiado distantes unas de otras; las separa una línea muy delgada, fluctuante, moviente, donde lo uno puede trocar en lo otro.

El silencio sería una condición básica e insoslayable para que el cuerpo pueda conectarse con esa parte del sujeto, algo de lo Real que quedaría a salvo de la captura mercantil. El cuerpo sinthomático ${ }^{5}$, es decir el que singulariza a cada quien, ha de aguzar sus sentidos para aproximarse a aquello que lo perturba, que lo conmueve, que le produce placer o el plus de goce destructivo. Es preciso tener en cuenta $-y$ a veces focalizar la atención en- las manifestaciones corporales para sentir el acoso insidioso de lo Real, vérselas con él. Desde ese encuentro conflictivo y perturbador, el sujeto emite un juicio y toma decisiones. Ese "pedazo" de lo Real es lo único seguro con que cuenta el sujeto en su singularísima realidad, por fuera de la Ley, por fuera del discurso del Amo, por fuera del Otro (2016a 73).

La separación entre la instancia singular, que puede contener una dosis de libertad vivificante, y lo ominoso, aliado de la destrucción y la muerte, es sutil, móvil, fluctuante. Solamente la palabra permite el acercamiento tentativo a ese mundo subterráneo, mudo, que habita en

5 Alemán emplea el término con una grafía que introduce un matiz diferencial para distinguirlo de los "síntomas" que aparecen con características similares en muchas personas. "El sínthoma de cada uno nombra la radical y singular Soledad del sujeto en el instante en que se separa de las figuras del Otro" (2016a 160,161). 
nuestro cuerpo; mundo que, por ser intangible, inaudible, inaccesible e inescrutable, admite ser engañosamente relegado al desván de las experiencias, imágenes, cosas que resultan molestas o incómodas en el diario trajinar por la vida.

Ahora bien, quienes están convencidos de que esa dimensión es determinante en el curso de la vida de cada quien, de sus victorias y de sus fracasos; que el estado de un cuerpo que flaquea o, por el contrario, se colma de vigor está estrechamente vinculado con lo que ocurre en el rincón más oscuro de sí mismo, en ese caso habrá un querer acercarse a esa especie de submundo y se busca la permanencia momentánea en el mutismo. Mientras se evocan experiencias vividas, imágenes fantasmáticas, sueños, anhelos, la atención se centra en la sensación muscular, su tensión o su relajamiento, la emotividad que delata el ritmo respiratorio o el ritmo cardíaco, entre otras manifestaciones fisiológicas y sensitivas. Es cierto -Freud y Lacan nos enseñan-, nada de ello adquiere significación relevante para sí mismo y para los otros si no se traduce en representaciones. Pero, según los maestros del psicoanálisis, este es un trabajo meramente intelectual, escindido de la sensibilidad y de los afectos. La negación de lo reprimido es uno de los recursos que utiliza el intelecto en el reacomodamiento discursivo.

Se ve como la función intelectual se separa aquí del proceso afectivo. Con la ayuda de la negación es enderezada solo una de las consecuencias del proceso represivo, a saber, la de que su contenido de representación no llegue a la consciencia (Freud 1992 254).

Esta es una realidad históricamente sedimentada en la cultura occidental, presente en una constancia habitual y cotidiana. El trabajo psicoanalítico con pacientes en tratamiento lo pone en evidencia. Nosotros, desde una perspectiva filosófica que refuta la supuesta omnipotencia del intelecto en su pretensión de comprender al ser humano y su mundo, y que, por el contrario, es muy hábil en su capacidad de embozar, disfrazar y distorsionar, apostamos a un pensar que, mientras hilvana ideas, puede ligar sus elucubraciones, asociarse, no dejar de atender a lo que ocurre en las sensaciones corporales, en la 
emotividad, en la sensibilidad. La significancia de la palabra resultante será otra muy diferente si la actividad inteligente procura no disociarse de lo que acaece en el cuerpo mientras el pensar procesa su trabajo.

\section{El silencio de la soledad nietzscheana}

Primo Levi afirma que hizo el acopio de información porque vio que era necesario, reiteramos, para estudiar con serenidad algunos aspectos del alma humana. Estamos convencidos de esa necesidad.

Con esto no pretendemos expresar nostalgia por la filosofía contemplativa, ni por los diversos espiritualismos. Nietzsche brindó un relativo apoyo al positivismo, como paradigma de reacción al excesivo ensimismamiento del pensar ${ }^{6}$; pero en su genial trabajo de madurez, la Genealogía de la moral, Nietzsche (1986) afirma que el hombre es el ser más lejano para sí mismo. Esa lejanía, en tanto extrañamiento de sí, se profundiza día a día. Por eso hoy, tal vez sea preciso poner el acento en la instancia de recogimiento silencioso que atraviesa el proceso del pensar.

Por otra parte, existe el silencio que todos los seres humanos, a excepción de quienes irremediablemente sucumben en el trato deshumanizante, pueden vivenciar; modo que, a nuestro entender, acrecienta las fuerzas vitales. El silencio temido y evitado es el de la soledad resultante del abandono, de la ausencia, de la extrañeza, tal como ocurre hoy en la sociedad tecnológica, en la cual la muchedumbre se agolpa en los centros urbanos, se aturde en medio del constante bullicio, en el ritmo vertiginoso de la vida cotidiana, $y$, en esa marea, se pierde. Estímulos sonoros y visuales asedian la intimidad e inhiben la posibilidad del encuentro consigo mismo y con el otro, alimentando el profundo silencio de la incomunicación.

6 Especialmente, hacemos referencia al periodo intermedio de su producción, que, sin quebrar la coherencia de la totalidad de su obra, difiere de sus escritos juveniles y de los que aparecen en la última etapa de su vida. 
Diferente es el sentido de la soledad silenciosa, que Nietzsche elogia cuando invoca las compañías que nunca lo abandonan: la vida y su propia alma. Lo expresa a través de su personaje predilecto: Zaratustra. El diálogo consigo mismo prospera en rincones apartados, lejos de los hombres. Cuando el ruido de la "opinión pública" o la cháchara del último hombre, o las proclamas del cultifilisteo lo cercan, Zaratustra se retira y permanece callado, escuchando a su corazón, que se colma de espíritu dionisíaco. Acerca de Dioniso comenta: aquel dios oculto "[...] cazarratas nato de conciencias [...], que a todo lo que es ruidoso y se complace en sí mismo lo hace enmudecer y le enseña a escuchar, que pule las almas rudas y les da a gustar un nuevo deseo" (1983 252). Se trata de una instancia subjetiva que promete fecundidad.

Claro que la hondura de la autorreflexión nietzscheana, capaz de tocar y enfrentar las capas subterráneas del alma, cual topo que horada la tierra hasta encontrar incluso lo más desagradable y vergonzante, digamos, esa capacidad y ese coraje, no es común en el rebaño humano. En los rincones más ocultos del alma reina el silencio que alberga la dimensión inconsciente a la que es preciso considerar al menos en sus irradiaciones proyectadas en el movimiento autorreflexivo.

Para Elena Nájera (2016)7 , el distanciamiento de la "esfera pública", en Nietzsche, es reivindicatorio de una "vida privada" silenciosa, la que otorga "sentido y valor" a la existencia (63). Sin negar el aserto de la filósofa española, interpretamos que el retiro a la soledad no significa renuncia definitiva a la relación con sus semejantes; los límites proceden más bien del carácter intempestivo de su obra. Si aceptamos que Zaratustra representa un boceto del suprahombre, habremos de tener en cuenta sus discursos, los cuales transmiten la añoranza de una comunión de amigos que comprendan su mensaje. Acordamos en un todo con la filósofa española cuando afirma que Nietzsche

7 Si bien la filósofa aborda el tema del silencio desde la defensa de una moral individual autoformadora, que resta legitimidad a la idea ilustrada de ciudadanía, tema que no tratamos en este escrito, su reflexión se aviene a este trabajo y aporta riqueza cuando establece que el silencio y la soledad constituyen vías de apertura hacia el sentido y la valoración de la existencia. 
desdeña el discurso crítico para dar lugar a la constancia silenciosa de "la propia forma de vida" (2016 63). Es preciso aclarar, junto con ella, que Nietzsche no defiende el individualismo. Los individuos son un producto de la democracia moderna que pretende igualarlos en torno al modelo liberal, desechando el pathos de la distancia que afirma la diferencia singularizante (Molina 2017).

¿Qué nos aporta Nietzsche hoy con la enseñanza de su praxis silenciosa, esa que no significa clausura de convento, pues no se trata de abandonar el mundo, sino de habitarlo desde el "pathos de la distancia"?

Nietzsche expresó un enérgico repudio por los periódicos formadores de la engañosa opinión pública. Entonces, se requiere la distancia para reelaborar interpretaciones ligeras, hechas desde el rumor, desde la repetición de eslóganes procedentes de vericuetos legales, construidos sobre la base de distorsiones, de dichos que circulan a partir del lanzamiento en condicional de una noticia; gran parte de lo cual llega a la población de modo recurrente y se reproduce y construye una realidad indeseable. Realidad, con la que, sin embargo, quienes se dedican a la filosofía o reflexionan sobre lo acontecido desde otro lugar o disciplina, tienen que habérselas.

La distancia sería un modo del ensimismamiento necesario para observar el acaecer a vuelo de pájaro, como el del filósofo pájaro nietzscheano, que contempla desde la altura perspectivista, pero que no se desconecta de la vida sensible; permanece atento a los afectos y sensaciones que recorren el cuerpo, que considera sus inclinaciones pulsionales, sus necesidades, sus deseos, incluso sus alteraciones fisiológicas, mientras el intelecto discurre. Por lo tanto, no se trata de una mirada aséptica. Las palabras mediante las cuales se configuran las ideas son tanto más engañosas cuanto más se alejan de la vida sensible (Molina 2017).

Sería un retiro transitorio, estado provisional (como la moral provisoria de Descartes), y no un modo de trabajo filosófico permanente; sería un poner entre paréntesis ideas consabidas, necesario para reacomodar el ojo y el oído, y así retomar el diálogo inter e intrasubjetivo desde un 
lugar diferente. Se trataría de un posicionamiento que abriría la posibilidad a una praxis que, sin desconocer la crítica, pudiera trascenderla; una praxis capaz de producir una fisura en "lo igual" e introducir una novedad potenciadora de la fuerza a favor de lo humano. Pensamos que hay circunstancias históricas e incluso instancias de la vida cotidiana en las que el silencio es el guardián y el protagonista primordial.

De acuerdo a lo antedicho, pensamos que el silencio, a veces olvidado por la aceleración del tiempo en el rendimiento económico productivo, tiene un potencial tal vez desconocido. En ese sentido, ciframos nuestra esperanza en la práctica de la escucha, como Nietzsche sostiene. En un estar y alejarse de la vida pública, como lo hace Zaratustra cuando el pueblo se ríe de él (Nietzsche 1995 38). Escuchar a la propia alma significa centrar la atención en las voces divergentes, disímiles, contradictorias, externas e internas, constitutivas de la condición humana, que se hacen cuerpo calladamente, aunque no siempre sean captadas en un registro consciente.

Esta actividad requiere del difícil ejercicio de poner en entredicho los mandatos sociales, afectivos, culturales, que operan automáticamente en la mayoría de los casos; poner en duda su legitimidad, aunque ella no goce de prestigio en un mundo acosado por la aceleración, que subvierte la actitud reflexiva transformándola en acciones cotidianas rutinarias, embozadoras de dogmas y prejuicios. En la actualidad, el pensar es arrebatado fundamentalmente por seductoras sugerencias de consumo impuestas por la economía de mercado. La duda que desencadena la acción reflexiva también marcha a contrapelo de la actividad mecánica y de la eficacia productiva, de modo que la valoración positiva de la capacidad de dudar se ve disminuida día a día. Sin embargo, pensamos que es necesario invocarla desde el silencio que también es demora, quietud, cierre provisorio de ventanas de la conciencia para sentir la tristeza, la alegría, los afectos y las necesidades desde su base corporal ${ }^{8}$. La multiplicidad de voces que confluyen en la constitución de la subjetividad se torna audible en el silencio. Nietzsche

8 Para un análisis más profundo del tema, véase Molina, S. Leticia. 2017, Capítulo 7. 
pone en boca de Zaratustra el clamor: " ¡Silencio! ¡Silencio! Ahora se oyen muchas cosas", e invita a los hombres superiores a caminar en la noche, cuando es posible escuchar "cosas a las que no les es lícito hablar alto", ahora "cuando también el ruido de vuestros corazones ha callado" (1995 424). En un recogimiento mudo se aproxima la posibilidad de dirimir entre voces amenazantes, transmisoras del miedo paralizante, o del ruido superfluo y adormecedor, y aquellas otras voces portadoras de "cosas" nuevas, tentadoras, embriagantes, llenas de futuro.

¿Cómo no rendir homenaje a la vida en toda su potencia, cómo no glorificarla como lo hace el filósofo a través de Zaratustra, su personaje predilecto, si ella es capaz de crear hasta en aquellos espacios donde el terror paralizante y la acción aniquiladora imperan incesantemente, donde lo Real, en su faz mortífera, desata la pulsión de muerte en un acto ininterumpido?

En este sentido, el testimonio de Primo Levi (1987) es elocuente. En relación con ello podemos mencionar una circunstancia por demás excepcional: en enero de 1945, cuando el ejército soviético incendió las barracas provocando la dispersión de los comandos alemanes, quedaron abandonados los enfermos entre los que se hallaba Levi. Se encontraban inermes, débiles, bajo temperaturas bajísimas y el frío colándose por los vidrios rotos, sin alimentos y prácticamente desprovistos de ropa. En ese contexto, donde hasta el día anterior regía en el Lager la ley que decía "come tu pan y, si puedes el de tu vecino" (96), comenzaron a brotar algunos signos de recuperación de humanidad: organizarse para conseguir carbón, estufa, abrigos y algún alimento que hubiese quedado en las ruinas, entre el humo y los restos de fuego, producto del bombardeo. Luego distribuir los beneficios en el grupo. "Fue aquel el primer gesto humano que se produjo entre nosotros. Creo que se podría fijar en aquel momento el principio del proceso mediante el cual, nosotros, los que no estábamos muertos; de Häftlinge empezamos lentamente a volver a ser hombres" (Ibíd.). Era un grupo de once hombres, con un mínimo de provisiones encontradas y ahora, afirma Levi, "nos unía un lazo" (Ibíd.). Es decir, que, según la experiencia relatada aquí, cabe la posibilidad de pensar 
que la fuerza que desencadena la violencia, el odio, la reducción progresiva de la humanidad, fuerza impulsada por el terror y el ultraje, puede revertir, trocar su sentido si las condiciones existenciales se modifican. ¿Qué ocurre en el oculto, inaprehensible, inaudible, misterioso movimiento subjetivo, en el que lo Real produce deslizamientos que el sujeto no puede asir? Muchos años antes, Nietzsche se sirvió del mito dionisíaco para tratar de comprender algo de lo que ocurre allí, en esa dimensión enigmática, contradictoria y ajena a principios ideológicos, culturales y morales.

Las condiciones de mantenimiento de la vida como fuerza de trabajo esclavo era la única que se cuidaba mínimamente hasta su agotamiento, o hasta el momento de la selección para ser conducido a los hornos. El fin perseguido por las SS era demostrar que los prisioneros no eran seres humanos; para ello había que despojarlos de absolutamente todos los recursos, objetos culturales básicos, albergue, sustraerles toda posibilidad de satisfacción de las necesidades que trascendieran mínimamente la supervivencia como fuerza de trabajo reducida al automatismo: máquinas dirigidas en movimiento vivo, obedeciendo órdenes como bestias domadas. Despojados de ropa, utensilios, intimidad, alimento, agua, higiene, resguardo del frío, palabra, nombre, familia. Desnudos, sin pelo, amontonados en la barraca, en un número tan alto que terminaban conformando una masa viviente informe (Levi 1987 76); enmudecidos por gritos siniestros, por golpes feroces, en el cumplimiento de un reglamento irracional.

En esas condiciones, muchos prisioneros adoptaron comportamientos fríos y monstruosos con sus compañeros, mientras otros pudieron evitar la deshumanización. Compartieron instancias de canto en los escasos momentos en que ello era posible, hasta crearon canciones, y desarrollaron habilidades estratégicas para obtener algún elemento necesario o material para fabricarlo rudimentariamente, en una apuesta no solo por la supervivencia, sino también en la sorda lucha por conservar la dignidad. Tal el caso de la fabricación del objeto que cumplía la función de cuchara en un extremo y de cuchillo en el otro. La obtención de estos utensilios tenía un valor simbólico de gran relevancia, y su privación tenía el propósito de convencer a los 
prisioneros de que eran meros animales, pues los obligaba a lamer el potaje, tal como lo hacen los perros. Primo Levi comenta que en algún momento descubrió una gran cantidad de cucharas de plástico almacenadas en uno de los ámbitos del Lager. Estas experiencias extremas constituyen muestras inapelables del movimiento agónico del poder de la vida en su lucha con la muerte.

\section{Conclusiones}

El acicate que mueve nuestra reflexión deriva de la importancia determinante que asignamos a la categoría de "vida" en el marco de la filosofía de Nietzsche. El núcleo esencial en la noción de "vida" es el poder de su crecimiento, que puede hacerse efectivo en la medida en que la dimensión intelectual no se disocie de la dimensión sensible; es decir, que la potenciación de la vida requiere de la ligadura del pensar y del sentir; necesita que la construcción de ideas se realice sin dejar de atender a las necesidades, afectos, sensaciones, deseos que atraviesan el cuerpo. Pero en el movimiento de fuerzas configurador de la vida, según la misma perspectiva nietzscheana, también acaece su debilitamiento y aniquilación. Esta convicción nos lleva a conferir un lugar de suma relevancia al silencio, imprescindible en el proceso de acercamiento entre las dos instancias constitutivas de la condición humana. Profundizamos el análisis de esta realidad controversial con la guía del psicoanálisis. El registro de lo Real, en la tópica establecida por Lacan, es clave respecto del tema que nos ocupa, pues ese es el campo del mutismo.

El silencio es actor fundamental, con presencia activa y constante en la historia social, política, cultural, institucional y personal. Pero la presencia y las implicancias del silencio son escasamente perceptibles; por eso apelamos al relato testimonial de Primo Levi en relación con su experiencia en los campos de concentración nazi. Nos detenemos en situaciones de extrema inhumanidad, en las que el mutismo termina siendo la manifestación prevaleciente. La densidad de los sentidos del silencio resulta casi intangible, pues los ruidos perturbadores, la represión externa e interna, las palabras vacías y las marcas del 
cientificismo, ocultan su significado y su gravitación en la vida de las personas y de las comunidades.

Defendemos la tesis de Nietzsche acerca del fluir de los sentidos. Estos producen virajes, trastrocamientos, mutaciones en el devenir de las fuerzas. De ahí que, en determinados contextos, el silencio sea una de las modalidades de la violencia destructiva, uno de los recursos que el hombre usa para someter, y se erige en aliado de la muerte. Mientras que ciertas experiencias subjetivas son reveladoras de un silencio capaz de potenciar la fuerza de la vida y enaltecer al hombre.

El discurso argumentativo, la reflexión dialógica, el diálogo intersubjetivo, sin duda resultan imprescindibles en la interacción y comprensión humanas; pero está visto ya que el poder de la palabra es ambiguo, engañoso, con demasiada frecuencia sirve a propósitos encubiertos, utilitarios, inconfesables. Es cuestión aceptada que la palabra frecuentemente deja de estar al servicio del develamiento de verdades, ni siquiera de pequeñas verdades. Por eso insistimos en la necesidad de volver una mirada valorativa sobre la dimensión sintiente de cada quien; esto es, realizar el movimiento de flexión imaginativa sobre el propio cuerpo para poder percibir su sufrimiento, su placer, su goce, sentimientos que pivotean sobre los deseos y las necesidades. Allí, tendremos el coraje -o careceremos del mismo- de darnos cuenta de qué sentimientos suscitan las situaciones de injusticia, hasta dónde sentimos la fraternidad racial o el odio, la solidaridad o el desprecio frente al dolor de la opresión, del otro y del propio. Estos estados de la sensibilidad trazan la dirección de las valoraciones. Valoraciones de aprecio, cercanía, aprobación, amor; o valoraciones de extrañeza, rechazo, desprecio, indiferencia, hostilidad.

Cuando Primo Levi, ya en libertad, evoca los episodios más aterradores vividos en el Lager, importa rescatar y subrayar no solo el trabajo intelectual de la memoria, sino también la expresión de su sensibilidad al decir: "se nos hiela la sangre en las venas" (1987 29), e interpretar en el acto autorreflexivo eso que está ocurriendo en el cuerpo; pues sabido es que el relato de los sucesos tiene motivaciones, intenciones y finalidades disímiles, dependiendo del sujeto que lo enuncia, el 
contexto de enunciación y otros factores discursivos y no discursivos intervinientes Pensamos que esta actividad requiere del apartamiento y la soledad silenciosa: ¡silencio! jescuchad! Repetimos el reclamo de Zaratustra para percibir, contactar esa actividad fisiológica anímicamente sentida y, en este caso, verbalmente expresada.

La cultura occidental asiste a una saturación verborrágica aplastante, la que conlleva el bastardeo de la palabra. Demasiadas palabras, ríos de palabras desbordan, banalizan, vacían de sentido los actos transformadores de la vida humana. La sumersión callada en la interioridad, si es transitoria, atendiendo a las condiciones antedichas, es un factor potenciador de la vida.

\section{Bibliografía}

Alemán, Jorge. (2016b). Horizontes neoliberales en la subjetividad. Buenos Aires: Grama Ediciones, 2016.

Alemán, Jorge. (2016a). Soledad: Común. Políticas en Lacán. Buenos Aires: Capital Intelectual, 2016.

Espósito, Roberto. Communitas. Origen y destino de la comunidad. Buenos Aires: Amorrortu, 2003.

Freud, Sigmund. "La negación". En Obras completas, volumen IXX. El yo y el ello y otras obras (1923-1925). Buenos Aires: Amorrortu, 1992.

Kaufman, Alejandro. "Sobre el silencio y las palabras: Vaticano y dictadura". La Tecla@Eñe. 2013.

Lacan, Jacques. Ética del Psicoanálisis, Seminario 7, Buenos Aires: Paidós, 2000. Levi, Primo. Si esto es un hombre. Barcelona: Muchnik Editores, 1987.

Levi, Primo. Los hundidos y los salvados. Barcelona: Muchnik Editores, 1989.

Llinares, Joan. "El silencio y la música en los Lager. Lectura de 'La trilogía de Auschwitz', de Primo Levi", Quaderns de Filosofía, 3/1 (2016): 91-106.

Molina, S. Leticia. El cuerpo y el devenir de las fuerzas en Nietzsche. Buenos Aires: Biblos, 2017.

Nájera, Elena. "El silencio como recurso del individuo en Thoreau y Nietzsche", Quaderns de filosofía, 3/1 (2016): 51-69. 
Nietzsche, Friedrich. Así habló Zaratustra. Trad. Andrés Sánchez Pascual. Buenos Aires: Alianza, 1995.

Nietzsche, Friedrich. Escritos sobre retórica. Trad. Luis Enrique de Santiago Guervós. Madrid: Trotta, 2000.

Nietzsche, Friedrich. Genealogía de la moral. Trad. Andrés Sánchez Pascual. Madrid: Alianza, 1986.

Nietzsche, Friedrich. Más allá del bien y del mal. Trad. Andrés Sánchez Pascual. Buenos Aires: Orbis, 1983.

Schwartzmann, Felix. El sentimiento de lo humano en América. Santiago de Chile: Universitaria, 1992.

Steiner, George. Lenguaje y silencio. Ensayos sobre la literatura, el lenguaje y lo inhumano. Barcelona: Gedisa, 2003. 